\title{
CFD Calculations of Soot Radiation Absorption Coefficients during Pool Tunnel Fire
}

\author{
Alon Davidy ${ }^{1}$ \\ ${ }^{\text {I }(\text { Safety Department/ Prime Minister Office, ISRAEL) }}$
}

\begin{abstract}
In this work a new algorithm has been developed in order to calculate the soot particles absorption coefficient during Heptane pool tunnel fire. It is based on the Fire Dynamics Simulator (FDS) results. In the FDS model, the combustion is represented by means of the mixture fraction with a single step chemical reaction model. Large Eddy Simulation (LES) is used to model the dissipative processes. HITRAN database was applied in order to calculate the refractive indices of soot particles $(n, k)$. CFD results show that the soot absorption coefficient is strongly influenced by the concentration and the temperature fields. It was found out that soot particle tends to concentrate near the tunnel ceiling. This phenomenon occurs due to thermal buoyancy forces. The thermal gradient causes the flow to flow towards the ceiling. This proposed algorithm can be implemented in smoke detection systems and in fire simulation codes.
\end{abstract}

Keywords: CFD, FDS code, Heptane, Tunnel Fire, Pool Fire, Hitran database, Soot particles concentration, Temperature field

\section{Introduction}

Tunnel development is proceeding to reduce transportation time and to achieve efficient use of space. Maintenance and management of these tunnels are now important, due to increased demand for greater use and the needs for construction of tunnels [1]. Therefore, because of increased usability of tunnels, the prevention of fire and emergency evacuation becomes important matters to consider. In particular, when fire occurs in a tunnel, there is a serious possibility of massive injuries to those trapped inside. In addition, substantial property damage is always expected. There were some cases of accidents: a missile propellant explosion at Dalseong tunnel in Daegu, Korea (2006); the Mont Blanc tunnel fire (1999) in France-Italy; and the Tauern tunnel fire (1999) in Austria, in which there were large numbers of casualties and huge property damage [2]. The cases above illustrate the reasons why an early-stage detection system is required, to reduce such losses. Therefore, we try to minimize such damage by developing a device that detects fire as early as possible.

In this work, a new algorithm has been developed in order to calculate the infrared radiation attenuation by soot particles, Carbon Dioxide, Carbon monoxide and water vapor inside tunnel fire. The computational work consists from two phases:

1) FDS software was implemented in order to calculate the temperature, soot, $\mathrm{CO}$ and concentration fields

2) HITRAN database was applied in order to calculate the refractive indices of soot particles (n, k) and the absorption parameters of the gaseous species

\subsection{CFD model}

\section{Theoretical MODEL}

The fire dynamics simulator (FDS) has been developed at the Building and Fire Research Laboratory (BFRL) at the National Institutes of Standards and Technology (NIST), e.g. McGrattan et al. [3, 4]. The program calculates the temperature, density, pressure, velocity, and chemical composition within each numerical grid cell at each discrete time step. It computes the temperature, heat flux, and mass loss rate of the enclosed solid surfaces. The latter is used in the case where the fire heat release rate is unknown. The following is a brief description of the major components of the model.

Hydrodynamic Model FDS code is formulated based on Computational Fluid Dynamics (CFD) of fire-driven fluid flow. The FDS numerical solution can be carried out using either a Direct Numerical Simulation (DNS) method or Large Eddy Simulation (LES). The latter is relatively low Reynolds numbers and is not severely limited in grid size and time step as the DNS method. In addition to the classical conservation equations considered in FDS, including mass species momentum and energy, thermodynamics based state equation of a perfect gas is adopted along with chemical combustion reaction for a library of different fuel sources.

Combustion Model For most applications, FDS uses a mixture fraction combustion model. The mixture fraction is a conserved scalar quantity that is defined as the fraction of gas at a given point in the flow field that originated as fuel. The model assumes that combustion is mixing controlled, and that the reaction of fuel and oxygen is infinitely fast. The mass fractions of all of the major reactants and products can be derived from the 
mixture fraction by means of "state relations," empirical expressions arrived at by a combination of simplified analysis and measurement [5].

Radiation Transport Radiative heat transfer is included in the model via the solution of the radiation transport equation for a non-scattering gray gas. In a limited number of cases, a wide band model can be used in place of the gray gas model. The radiation equation is solved using a technique similar to a finite volume method for convective transport, thus the name given to it is the Finite Volume Method (FVM) [3]. FDS also has a visual post-processing image simulation program named "smoke-view".

\subsection{HITRAN Database}

The HITRAN database project has its origins in compilations of spectral parameters for water vapor and carbon dioxide almost four decades ago[7] and culminated in the first public, machine-readable edition [7] in 1973. HITRAN has evolved from a compilation of parameters for the principal atmospheric absorbers in the infrared to a large database covering the microwave through ultraviolet regions, containing additional parameters for the demands of remote-sensing satellite experiments, and with many molecular constituents. Meanwhile, there has also been great progress in the acquisition of spectral parameters for trace gases, major improvements for the major gases such as water vapor and ozone, and the measurement of cross-section data for the "heavy" gases. HITRAN itself, the line-by-line portion of the compilation, is now part of a much larger ensemble of tools for modeling. First, the compilation includes HITRAN (significantly updated as always) and several other databases for the "matter" part of the modeling of the interaction of matter and radiation. In addition to HITRAN, the compilation has directories containing cross section data of heavier species or molecules with very dense spectral features, UV cross-sections and line-by-line parameters, supplemental files (such as for parameters in HITRAN-like format, but consigned to a subordinate folder because they may be better represented for simulation studies in the cross-section files), aerosol indices of refraction, the accompanying HAWKS software and documentation, and HITEMP, the high-temperature analogous database to HITRAN. Fig. 4 illustrates the file structure of HITRAN database [9].

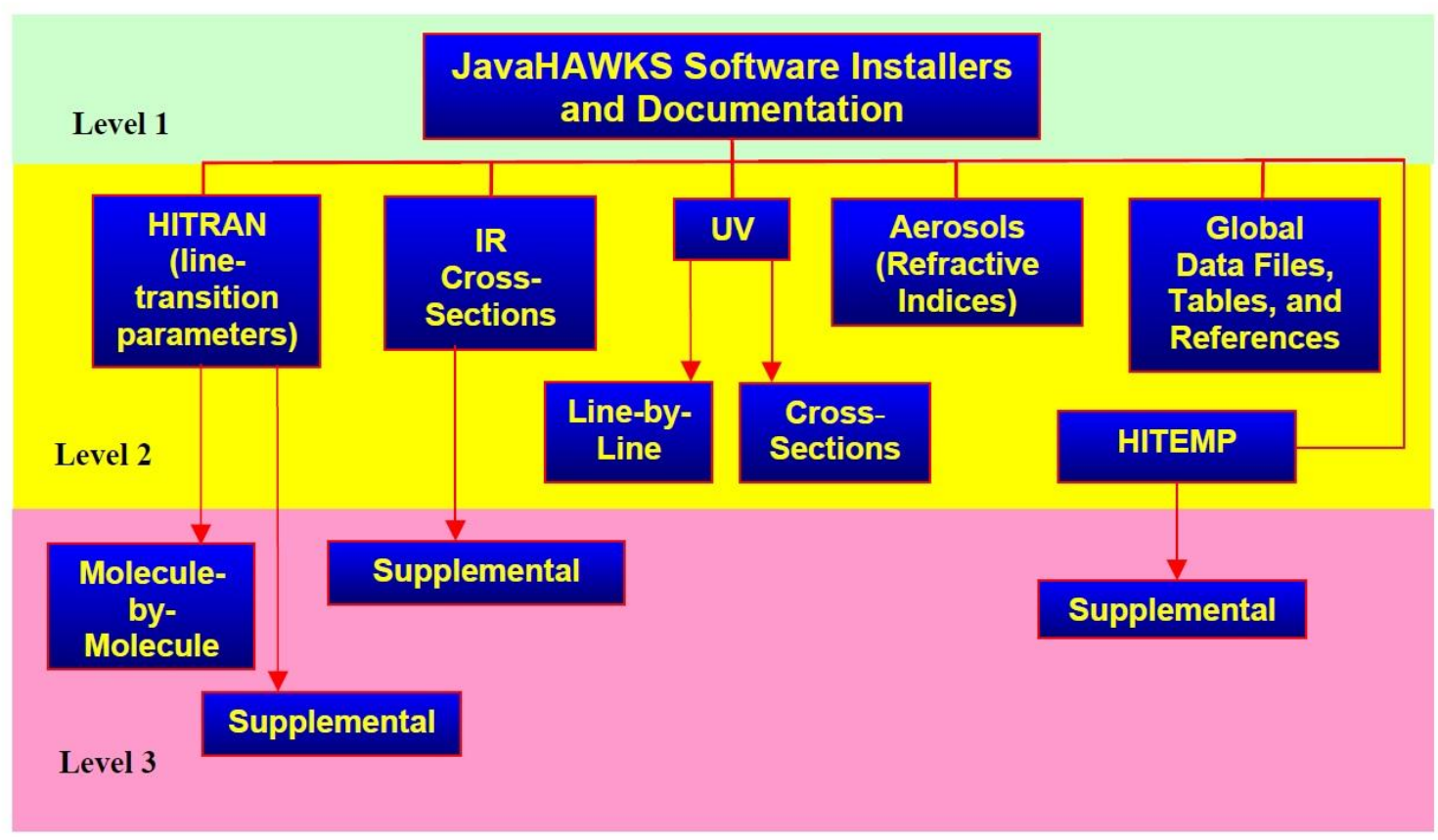

Fig. 4: File structure of HITRAN database [9]

\section{Description of CFD Calculations}

The dimensions of the tunnel were $20 \mathrm{~m}$ long, $7.4 \mathrm{~m}$ wide and $5 \mathrm{~m}$ high. It was assumed that the heptane fuel was burned. 12 thermocouples have been placed inside the tunnel. An oxygen concentration detector has been placed at the left corner of the tunnel. In this work, it was assumed that there isn't ventilation in the tunnel. The CFD simulation result will be presented in this section. One advantage of CFD simulation is that it can provide much detailed information on the fire, including the local and transient gas velocity, gas temperature, species concentration, solid wall temperature, composite burning rate, radiation heat transfer, convection heat transfer and heat release rate (HRR). 


\section{Results}

This section divided into two parts. In section 4.1 FDS results are shown. In section 4.2 the calculation of the soot absorption coefficient is presented.

\subsection{FDS Results}

The CFD simulation result will be presented in this section. One advantage of CFD simulation is that it can provide much detailed information on the fire, including the local and transient gas velocity, gas temperature, species concentration, solid wall temperature, composite burning rate, radiation heat transfer, convection heat transfer and heat release rate (HRR). The temperature field at $\mathrm{t}=9 \mathrm{~s}$ is shown in figure 5 .

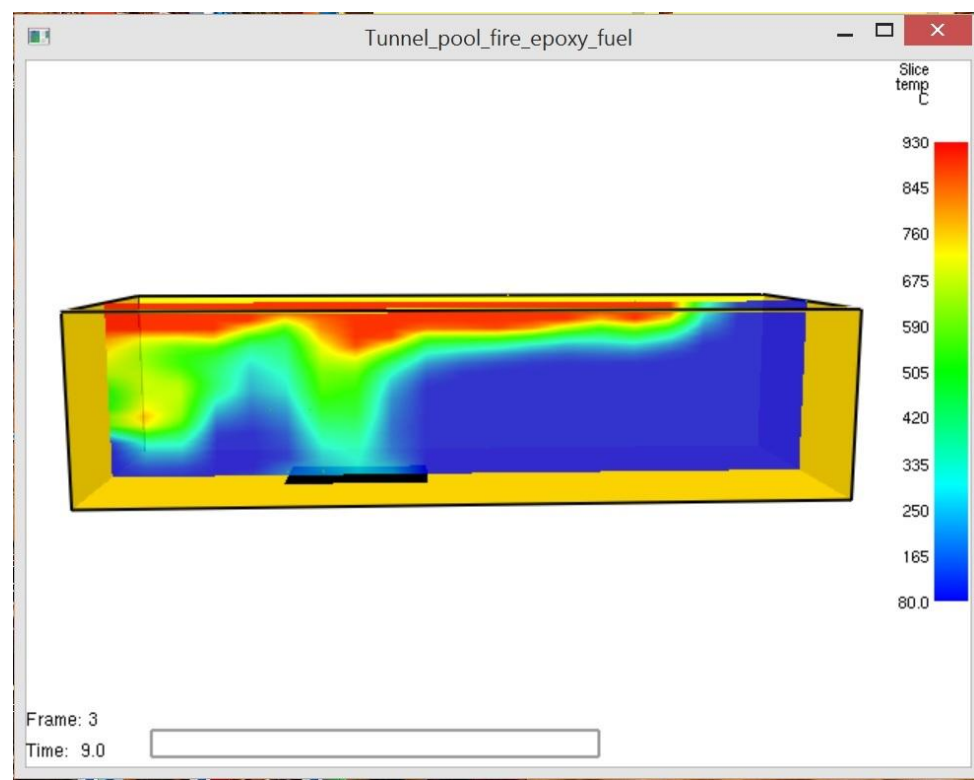

Fig. 5: Temperature field in the tunnel at $\mathrm{t}=9 \mathrm{sec}$

It can be seen from figure 4 that the ceiling temperature at time $=9 \mathrm{sec}$ approaches to $930^{\circ} \mathrm{C}$. The spatial concentration of the soot inside the tunnel is shown in figure 6 .

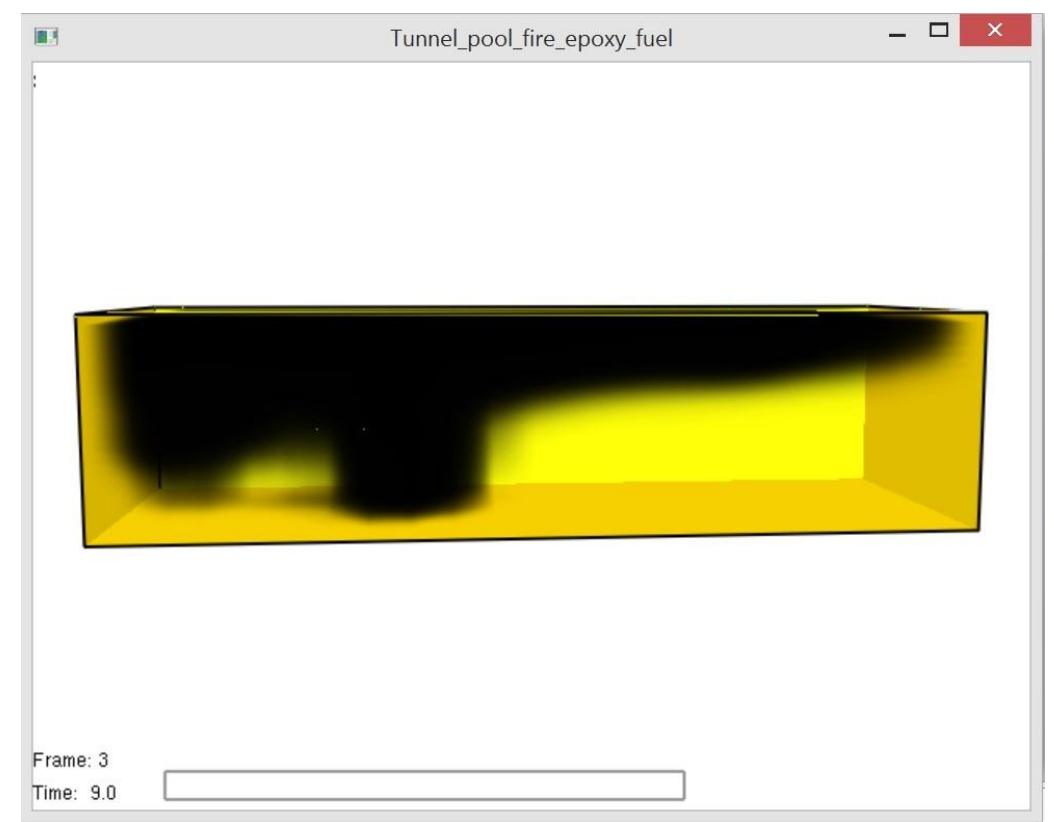

Fig. 6: Soot concentration field in the tunnel at $t=9 \mathrm{sec}$

It can be seen from fig. 6 the effect of "back layering". Back layering (also known as "back-flow") is the name given to the phenomenon when smoke from a fire is observed to move against the direction of the airflow in the tunnel [10]. The calculated oxygen mole fraction is shown in figure 7. 


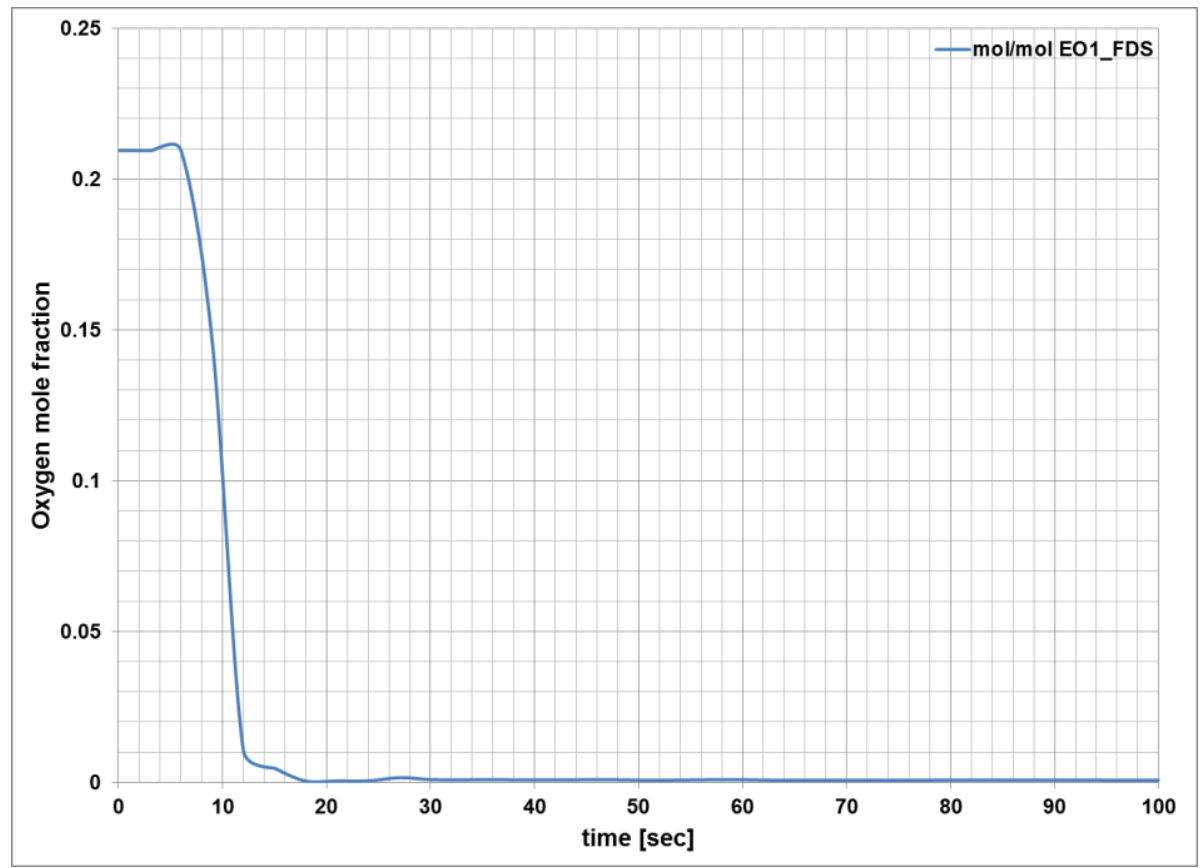

Fig. 7: Calculated oxygen mole fraction

Figure 7 shows that the combustion reaction causes the oxygen concentration to decrease.

\subsection{Calculation of the soot absorption coefficient}

The soot absorption coefficient is calculated according to [11]:

$$
\alpha=b_{1} \bar{\rho} Y_{\mathrm{S}}\left[1+b_{\mathrm{T}}(\mathrm{T}-2000)\right]
$$

Where $b_{1}=1232.4 \mathrm{~m}^{3} / \mathrm{kg}, \mathrm{b}_{\mathrm{T}}=4.8 \mathrm{E}-4 \mathrm{1} / \mathrm{K}, \bar{\rho} \mathrm{Y}_{\mathrm{S}}$ is the soot density and $\mathrm{T}$ is the temperature. The soot density and the temperature are calculated by FDS software. The soot density distribution as a function of $\mathrm{z}$ at $\mathrm{t}=300 \mathrm{sec}$ and $3000 \mathrm{sec}$ is shown in fig. 8 .

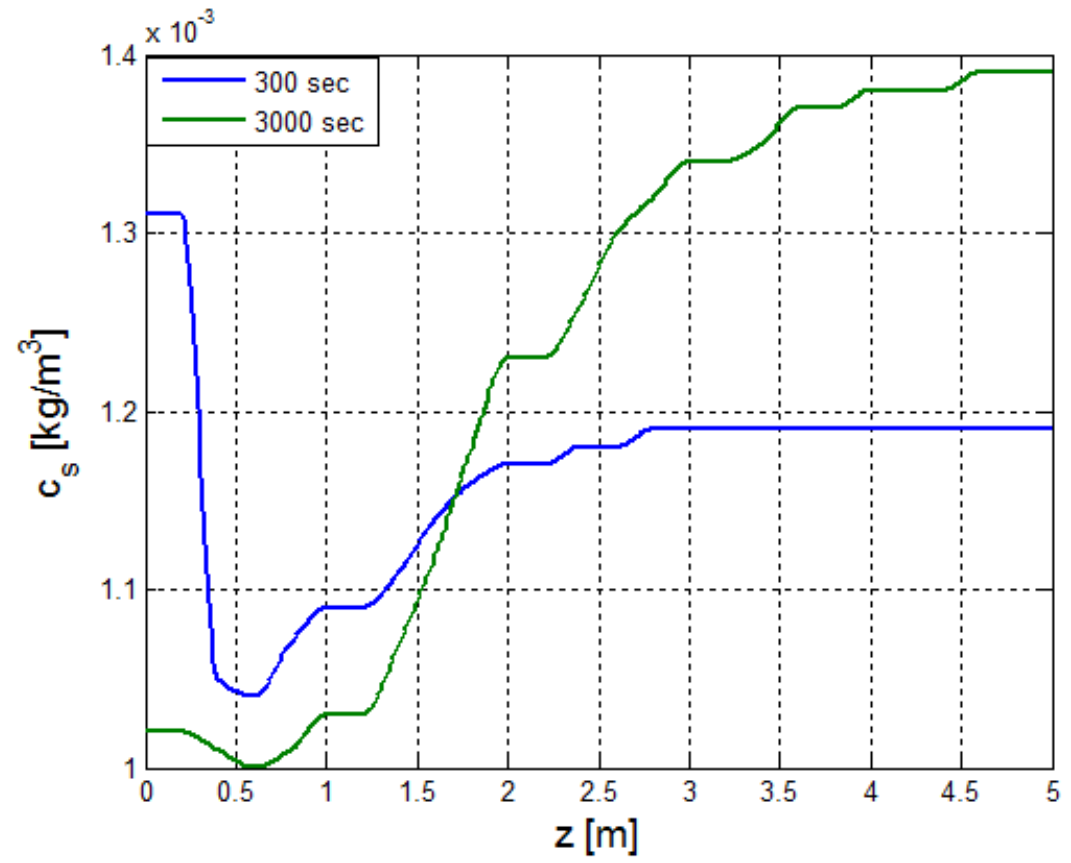

Fig. 8: The Soot concentration distribution along $\mathrm{z}$ axis.

From figure 8 it can be seen that the soot particles are concentrated near the tunnel ceiling. This phenomenon occurs due to thermal buoyancy forces (natural convection). The thermal gradient causes the flow to flow towards the ceiling. Figure 9 shows the velocity in $\mathrm{z}$ axis. 


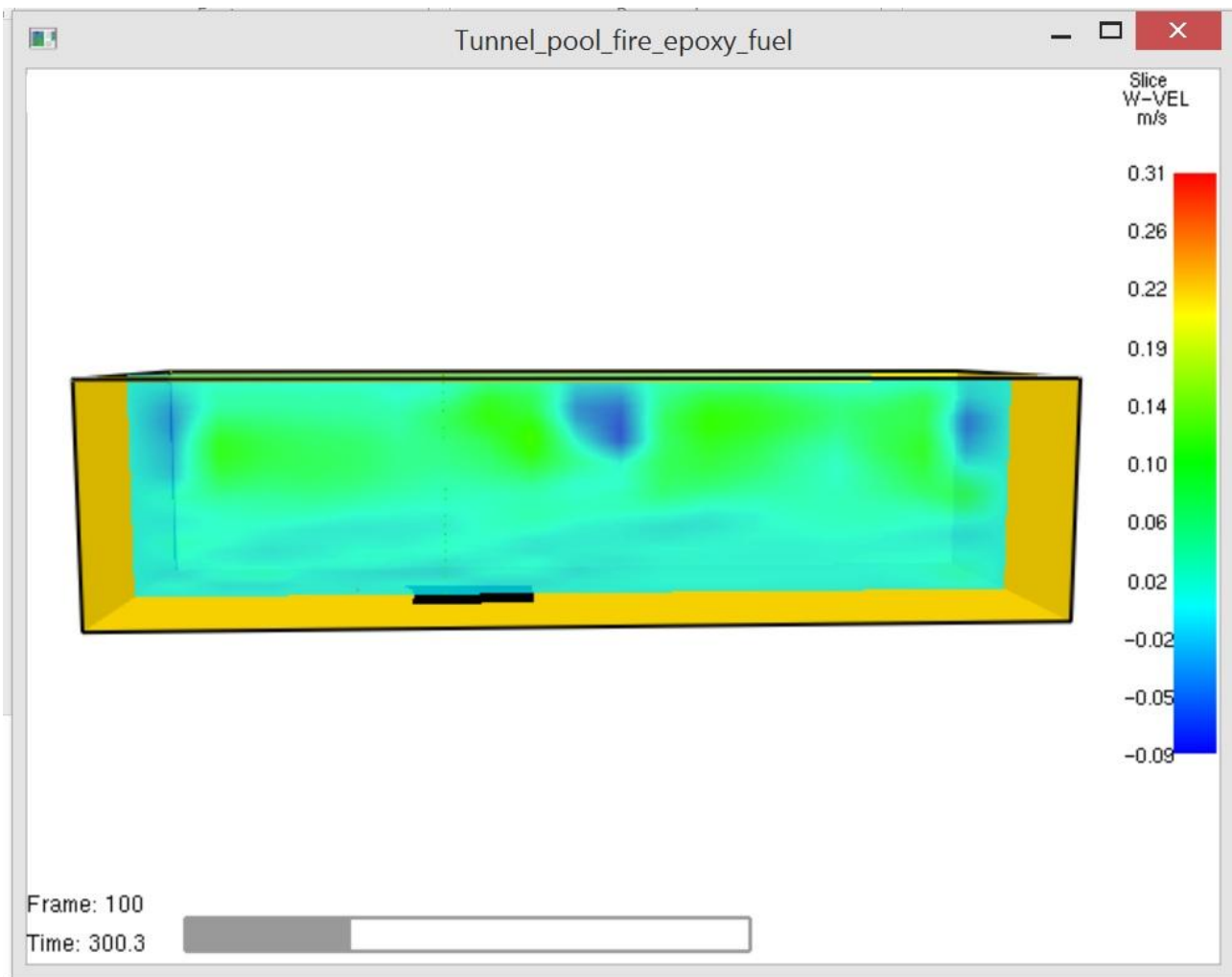

Fig. 9: Velocity field along $Z$ axis of the gaseous mixture

As can be seen from Figure 8, there is a flow of the exhaust mixture upwards. The temperature distribution along $\mathrm{z}$ axis at $\mathrm{t}=300 \mathrm{sec}$ and $3,000 \mathrm{sec}$ is shown in fig. 10.

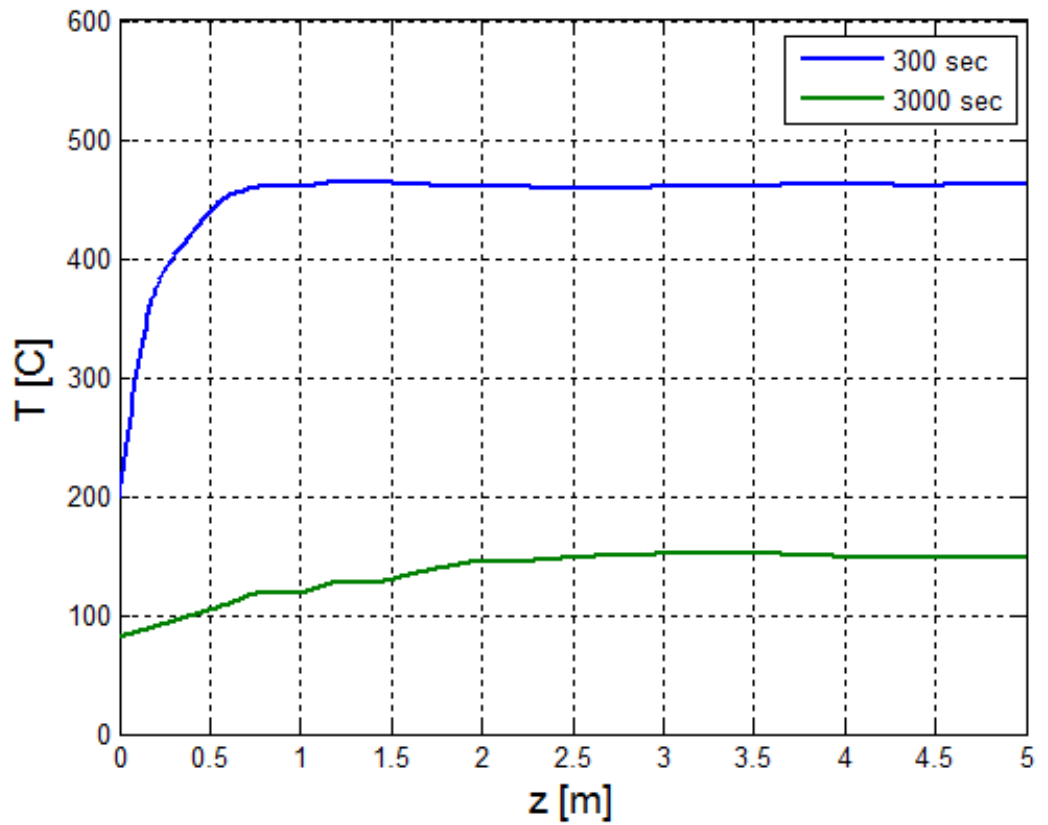

Fig. 10: The temperature distribution along $\mathrm{z}$ axis.

From fig.10 it can be seen that the temperature increases with $\mathrm{z}$. The temperature decreases with time. The maximal temperature of the gaseous mixture at $\mathrm{t}=300 \mathrm{sec}$ is $463^{\circ} \mathrm{C}$. The temperature of the gaseous mixture at $\mathrm{t}=3,000 \mathrm{sec}$ is about $150^{\circ} \mathrm{C}$. This phenomenon occurs because two reasons:

1) The gaseous mixture cools with time due to the radiation and convection to the tunnel walls

2) The Flame was extinguished as a result of the oxygen consumption.

Figure 11 shows $3 \mathrm{D}$ plot of the temperature of the gaseous mixture at $\mathrm{t}=300 \mathrm{sec}$. 


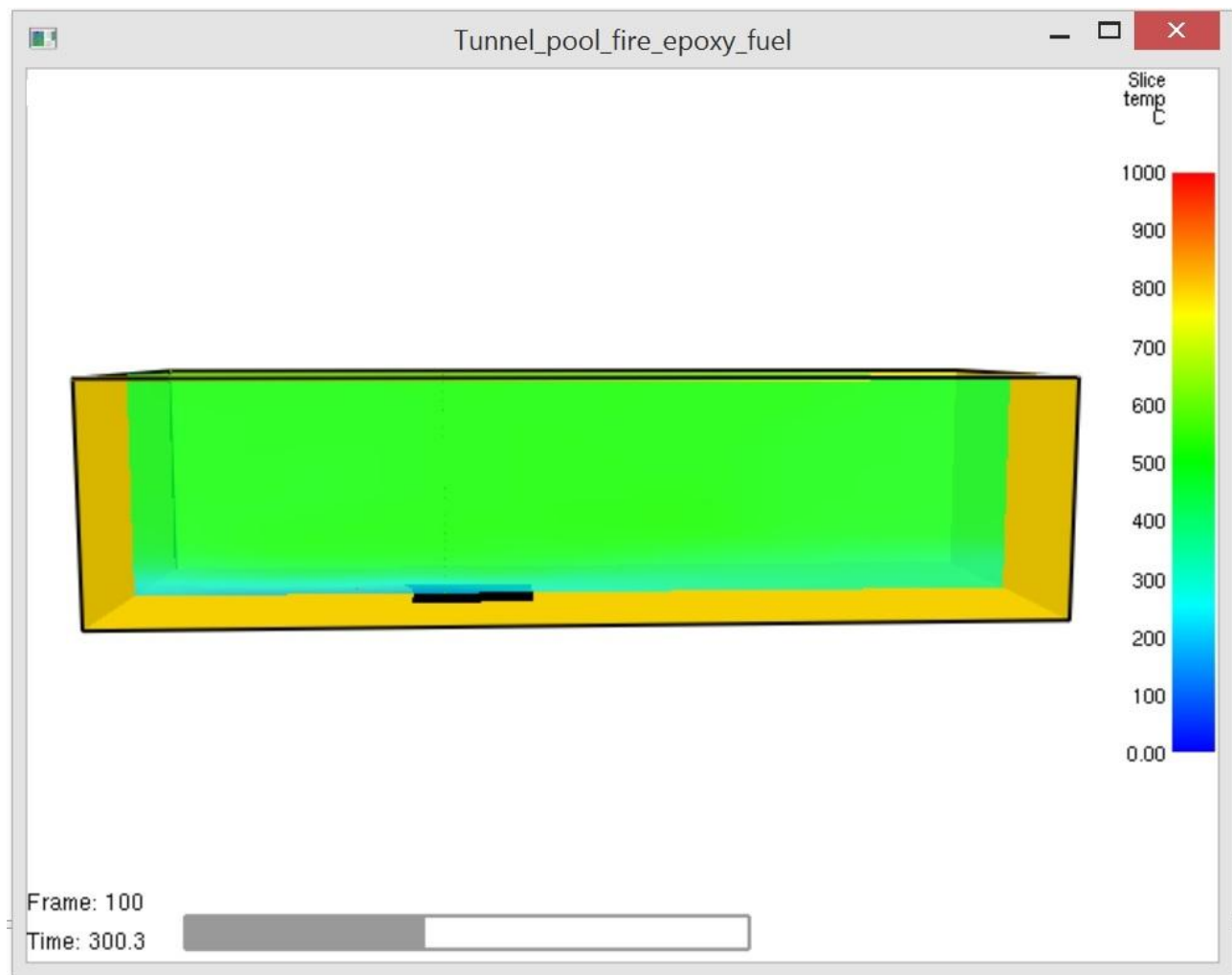

Fig. 11: 3D plot of the temperature inside the tunnel.

From fig. 11 it can be seen that the temperature inside the tunnel increases with $\mathrm{z}$.

The soot absorption coefficient as a function of $\mathrm{z}$ at $\mathrm{t}=300 \mathrm{sec}$ and $3000 \mathrm{sec}$ is shown in figure 12 .

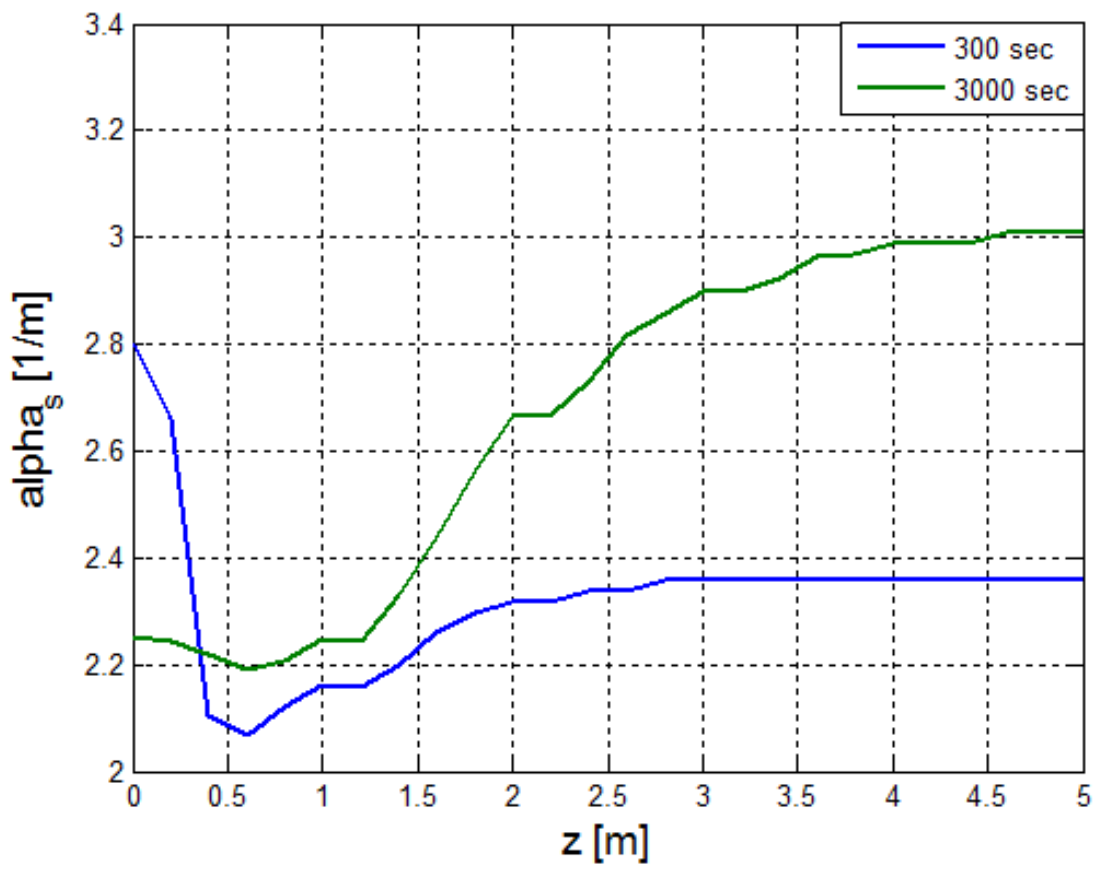

Fig. 12: The soot absorption coefficient distribution along $\mathrm{z}$ axis.

From fig. 12 it can be seen that the soot absorption coefficient increases with z. This is because the soot particles are concentrated near the ceiling (see fig. 8). 


\section{Conclusion}

This work describes a new radiation model applied in CFD calculations of pool tunnel fire scenario. This radiation code is implemented in the Fire Dynamics Simulator (FDS). The combustion is represented by means of the mixture fraction with a single step chemical reaction model. Large Eddy Simulation (LES) is used to model the dissipative processes. CFD results show that the extinction coefficient is strongly influenced by soot particle concentration field. A sensibility analysis has shown that the flame characteristics are strongly affected by the soot yield. It was found out that the soot concentration increases near the tunnel ceiling. This phenomenon occurs due to thermal buoyancy forces. The thermal gradient causes the flow to circulate.

It was also found out that the temperature increases with the height. The temperature decreases with time. This phenomenon occurs because two reasons:

- The gaseous mixture cools with time due to the radiation and convection to the tunnel walls

- The flame was extinguished because of the oxygen consumption.

\section{References}

[1]. Han, D. \& Lee, B., Flame and smoke detection method for early real-time detection of a tunnel fire, Fire Safety Journal, 44:951956, (2009).

[2]. Alessandro G. Colombo, Nedies project: lessons learnt from tunnel accidents, in: JRC-ISIS EUR Report on March 2001.

[3]. McGRATTAN, K. Fire Dynamics Simulator (Version 5) - Technical Reference Guide Volume 1: Mathematical Model, NIST Special Publication 1018, NIST, (2010).

[4]. McGRATTAN, K., FORNEY, G.P., Fire Dynamics Simulator (Version 5) - User's Guide. NIST Special Publication 1019, NIST, (2010).

[5]. McGRATTAN, K., 2005, Numerical Simulation of the Caldecott Tunnel Fire, April 1982, NISTIR 7231.

[6]. Eisner, H.S. \& Smith, P.B. "Convection Effects from Underground Fires: the Backing of Smoke against the Ventilation" Research Report no. 96, Safety in Mines Research Establishment, (1954)

[7]. D.M. Gates, R.F. Calfee, D.W. Hansen, and W.S. Benedict, "Line Parameters and Computed Spectra for Water Vapor Bands at 2.7 $\mu \mathrm{m}$," NBS monograph 71 (1964); R.F. Calfee and W.S. Benedict, "Carbon Dioxide spectral line Positions and Intensities Calculated for the 2.05 and 2.7 Micron Regions," NBS Technical note 332, 1966.

[8]. R.A. McClatchey, W.S. Benedict, S.A. Clough, D.E. Burch, K. Fox, L.S. Rothman, and J.S. Garing, "AFCRL Atmospheric Absorption Line Parameters Compilation", AFCRL Technical Report 0096, 1973.

[9]. Laurence S. Rothman, John Schroeder and Kuilian Tang, Java HITRAN Atmospheric Workstation Manual, Atomic and Molecular Physics Division Harvard-Smithsonian Center for Astrophysics, 60 Garden St, Cambridge MA 02138-1516, April 2003.

[10]. Eisner, H.S. \& Smith, P.B. "Convection Effects from Underground Fires: the Backing of Smoke Against the Ventilation" Research Report no. 96 (1954). Safety in Mines Research Establishment.

[11]. Sazhin, S.S., An Approximation for the Absorption Coefficient of Soot in a Radiating Gas, Fluent Europe L. 